\title{
Inductances Calculation of Permanent Magnet Synchronous Machine
}

\author{
Bellal Zaghdoud and Abdallah Saadoun
}

\begin{abstract}
The accurate determination of permanent magnet synchronous machine (PMSM) inductances has been the subject of much research over a long time. For these reason, this paper present the calculation of the direct and quadrature inductances of permanent magnet synchronous machine by the finite element method (FEM), where the calculation of these parameters is based on the air gap magnetic field distribution which is the basis of the analysis of performance electric machines. The numerical results are presented by diagrams, they discussed and compared by the experimental once, they show a very good agreement. This confirms the validity and effectiveness of the finite element method in solving of these problems
\end{abstract}

Index Terms-Finite element, inductance direct and quadrature, magnetic flux density, permanent magnet synchronous machine.

\section{INTRODUCTION}

Permanent magnet synchronous motors (PMSM) are widely used in high-performance drives such as industrial robots and machine tools for their advantages on high power density, high-torque, free maintenance and so on. In recent years, the magnetic and thermal capabilities of the PM have been considerably increased by employing the high-coercive PM materials [1]. In last few years, permanent magnet synchronous motor (PMSM) consequently is acquired in more and more far-ranging application, because of its properties such as small volume, light weight, high efficiency, small inertia, rotor without heat problem, etc. [2]. It is very important matter to calculate as accurate as possible the values of the parameters of the PMSM. Of the most important significance are the direct- and the quadrature- axis inductances, as they are determining corresponding synchronous reactances [3]; it is well known that they are the most significant parameters when dealing with steady state and/or dynamic performance analysis of PMSM. . Nowadays, permanent magnet synchronous motor is designed not only to be more powerful but also with lower mass and lower moment of inertia. We must into account the required accurate of the results also the reliability of testing procedures for determination of the machine parameters, when we develop permanent magnet synchronous motor model. The conventional methods of testing for determination of synchronous machine parameters cannot be applied in the case of permanent magnet machine. The only alternative to solve this problem is to use numerical methods [4]-[6].

Manuscript received November 10, 2013; revised March 13, 2014

The authors are with the Electrical Engineering Department, Badji Mokhtar University, P. O. Box12, 23000 Annaba, Algeria (e-mail: bellal.zaghdoud@gmail.com, a_saadoun@yahoo.fr).
During the last two decades the finite element method proved to be the most appropriate numerical method in terms of modeling, flexibility and accuracy to solve the nonlinear Poisson's equation governing the magnetic field who's concerned a principal element in calculation of machine parameters [5], [6]. Currently, several modeling of electrical machines softwares are available. The finite element package FEMM 4.2 (Finite Element Method Magnetic) developed by D. Meeker available for free on its website was used for the modeling of the PMSM.

\section{Resolution OF the Magnetic FiEld Problem With FEM}

The finite element method is a numerical procedure designed to obtain an approximate solution to a variety of field problems governed by differential equations. The solution domain is replaced by the problem of the subdomains of simple geometric shapes, called elements, in order to reconstruct the original domain by their assembly. The unknown variables of the considered field are then expressed by an approximate function called interpolation function [7], [8]. These functions are defined on each element using the values that the variable takes from the field on each node. Therefore the knowledge of nodal values and interpolation functions allow defining completely the behavior of the variable field on each element. Once the nodal variables, which are actually the unknown factors of the problem, are calculated, the values of the variables of the field on any point of the field can also be determined using interpolation function. The precision of the method depends not only on the dimensions of elements and their number but also the type of the interpolation function. As for the numerical method, the finite element method converges to the exact solution provided to increase the number of subdivisions of the solution domain and to ensure continuity of the interpolation function of its first derivatives along the borders of adjacent elements [5], [7].

The main steps for implementation of the finite element method [9] are described below.

\section{A. Pre-Processing}

After the problem geometry is defined we have to complete the entire domain of the electric machine by defining the material properties and boundary conditions. By imposing the vector potential zero at the outside diameter of the machine the magnetic field will be confined to the solution domain, while the periodicity conditions $A(0)=A(\pi)$ can restrict the solution domain to a double pole pitch. The basic idea of FEM application is to divide that complex domain into 
elements small enough, under assumption to have linear characteristics and constant parameters. Usually, triangular elements are widely accepted shapes for 2D FE models. After this step is completed, the output is always generation of finite element mesh. It is recommended to make mesh refinements in the regions carrying the interfaces of different materials, or with expected or presumed significant changes in the magnetic field distribution.

\section{B. Processing}

In order processing part to be executed and output results to be obtained system of Maxwell's equation should be solved.

\section{Post Processing}

Using the post-processor software, various results can viewed as the mapping of field lines and the intensity of the magnetic induction in different parts of the machine as shown in Fig. 1, however the main result of the simulation is the field distribution in the air gap which is given either in graphical form as shown in Fig. 2 or in the form of a table that provides the magnetic induction at a point as a function of the air gap of its curvilinear abscissa.

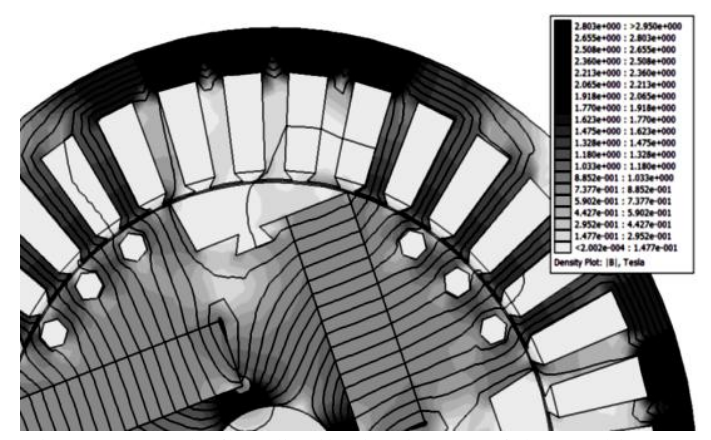

Fig. 1. Magnetic flux distribution in part of the machine.

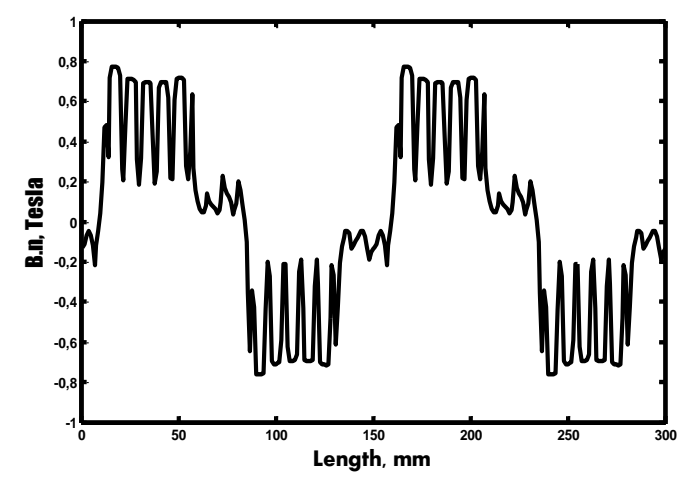

Fig. 2. Magnetic field distribution along the air gap.

\section{Discussion of the Simulating Results}

Examination of these curves shows that rapid variations of the magnetic field are mainly due to the presence of teeth and slots of the stator area. Such variations are predictable because the calculation of the field using an interpolation function of the first order results in the constancy of the field [4], [8] at each element of mesh. Moreover, the finite element solution is incomplete because the model is unable to take into account electromagnetic phenomena accompanying the rotation of the rotor. Indeed, in a real machine, the effect of oscillation of the field between the slots and teeth with induced eddy currents in the inner surfaces of the teeth, resulting in a local saturation of the interface zone air gap magnetic circuit [8]. For these reasons the field variations in a real machine are less pronounced.

\section{VALIDATION OF MAGNETIC FIELD DiSTRIBUTION RESULTS}

Fig. 3 shows the measured [10] and computed air gap magnetic field of the permanent magnet synchronous machine at no load and full load.
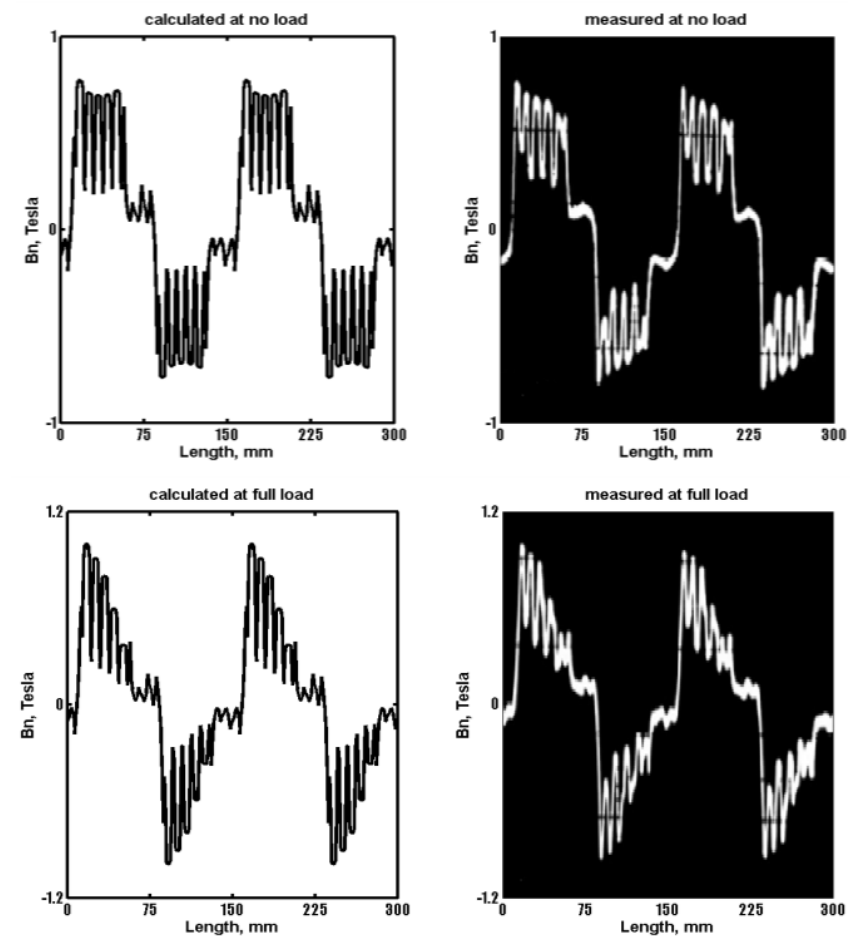

Fig. 3. Comparison between magnetic flux distribution results

Examination of these figures confirms the accuracy of the solution of the field problem by finite element method. Therefore, the determination of machine parameters that directly depend on its assessment can be made with confidence.

\section{FEM REACTANCE CALCULATION}

The calculation of reactances $X d$ and $X q$ respectively is obtained by simulating a system operating with a power factor of zero and unity power factor for different values of stator current.

Demagnetizing action is apparent in the first case, while the magnetic response causes distortion of the field distribution. Simulation of the magnetic armature reaction along the longitudinal axis, shown in Fig. 4 is obtained by canceling the magneto motive force (mmf) magnets [11], [12].

The calculation of the reactance is carried out from the numerical solution by applying

$$
L_{d}=\frac{\psi_{d}}{I_{d}}, X_{d}=\omega L_{d}
$$

The direct current corresponds to the moment when the stator currents are the values 


$$
i_{a}=I_{m}, i_{b}=i_{c}=-\frac{I_{m}}{2}
$$
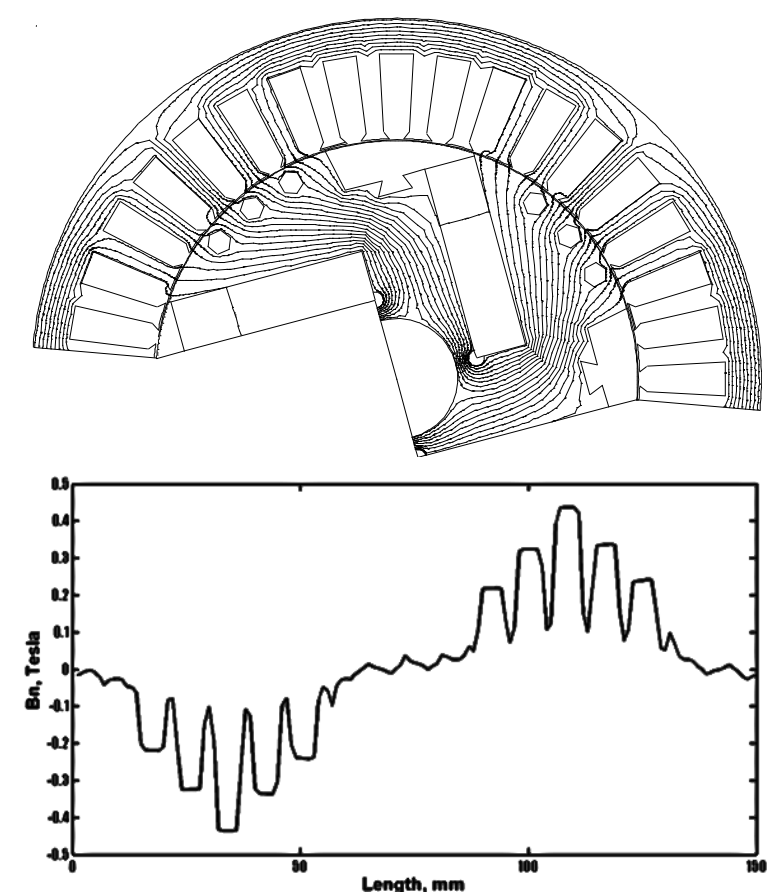

Fig. 4. Magnetic flux distribution for direct reactance calculation.

The calculation of the transverse inductance is effected in the same manner. The mmf of armature reaction is directed along the axis interpolar when the machine operates with a power factor of internal unity.

$$
L_{q}=\frac{\psi_{q}}{I_{q}}, X_{d}=\omega L_{d}
$$

Fig. 5 shows the distribution of the field lines and its distribution along the air gap
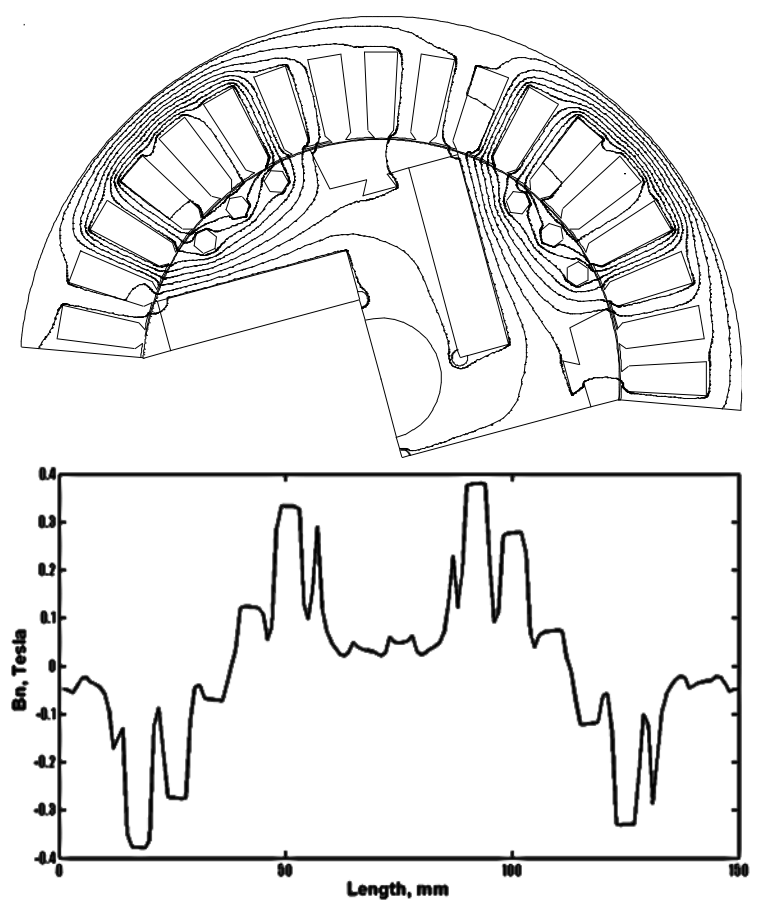

Fig. 5. Magnetic flux distribution for quadrature reactance calculation.
As it was assumed the fictitious direct/quadrature winding to have the same number of turns as the real stator phase winding, it is requested to introduce another factor to find the direct- and quadrature- axis inductance, respectively [13]. For a 3-phase AC machine, the armature current in the direct/quadrature axis would have to be $3 / 2$ times as great as the phase current to produce the same magneto-motive force along the respective axis as the three phase winding. Hence,

$$
L_{d, q}=\frac{L}{3 / 2}
$$

Fig. 6 shows inductances variation in rated regime as below:

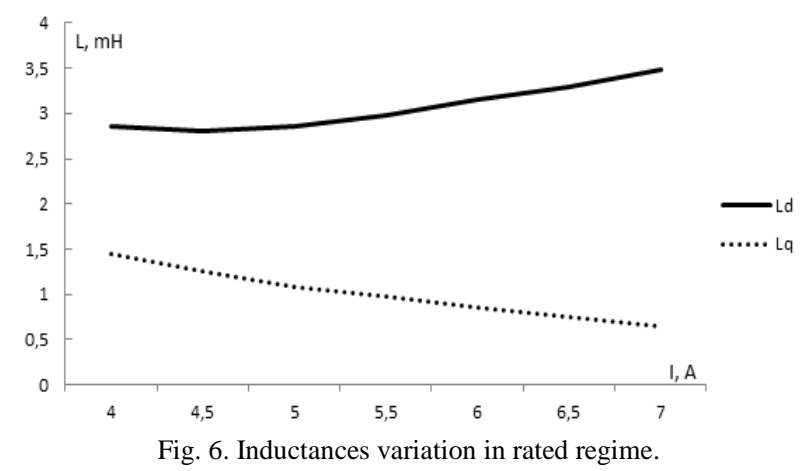

\section{CONCLUSION}

In the context of the determination of the direct and quadrature inductances of the synchronous permanent magnet machine, the resolution of the problem of the magnetostatic field by the finite element method was presented. FEMM software was used to obtain its numerical solution whose analysis has required the development of specific functions of processing. The results obtained by finite element method are very accurate. Moreover, the examination of measured results confirms this accuracy. On the other hand we can conclude that by using FEM results are obtained more easily and quickly compared to the other methods.

\section{APPENDIX}

Dimensions and material properties:

Outer diameter: $60 \mathrm{~mm}$

Stator inner diameter: $40 \mathrm{~mm}$

Rotor outside diameter: $39.619 \mathrm{~mm}$

Number of magnets per pole: 01

Number of pole: 04

Number of slots: 36

Number of conductors in series per phase: 156

Stator resistance: $0.378 \mathrm{Ohm}$

Rated power: $990 \mathrm{~W}$

Rated current: $5.5 \mathrm{~A}$

Rated speed: $1500 \mathrm{tr} / \mathrm{mn}$

\section{REFERENCES}

[1] I. Takahashi and T. Naguchi, "A new quick-response and high-efficiency control strategy of an induction motor," IEEE Trans. Ind. Appl., vol. IA-22, issue 5, pp. 820-827, 1986.

[2] Y. Li and X. P. Yan, "The perspective and status of PMSM electrical serro system," Micromotors Servo Technique, vol. 4, pp. 30-33, 2001 
[3] M. Hadef, M. R. Mekideche, A. Djerdir, and A. Miraoui, "An inverse problem approach for parameter estimation of interior permanent magnet synchronous motors," Progress in Electromagnetics Research $B$, vol. 31, no. 15, 2011.

[4] P. Silvester, "Finite elements for electrical engineers," Cambridge University Press, 1990

[5] P. Silvester and M. V. K. Chari, "Finite element solution of saturable magnetic field problem," IEEE Trans. on Power Apparatus and Systems, PAS-89, vol. 7, pp 1642-1651, 1970.

[6] G. O. Young, "Synthetic structure of industrial plastics," in Plastics, 2nd ed. J. Peters, Ed. New York: McGraw-Hill, vol. 3, pp. 15-64, 1964.

[7] K. J. Binns, C. P. Riley, and T. M. Wong, "The efficient evaluation of torque and field gradient in permanent magnet with small air gap," IEEE Transactions on Magnetics, vol. 21, no. 6, pp 2435-2438, Nov. 1985.

[8] M. Kostenko and L. Piotroski, Electric Machines: Alternating Current Machines, Moscow: Mir Publishers, vol. 2, 1963

[9] D. Meeker, "Finite Element Magnetics," User Manual for FEMM Ver. 4.2, Boston, Massachusets, USA, 2009

[10] A. Saadoun, "The analysis of the performance of a permanent magnet synchronous generator," M.Sc Thesis, University of Liverpool, Aug. 1989.

[11] D. Ban. Zarko, and R. Klaric, "Finite element approach to calculation of parameters of an interior permanent magnet motor," Automatika, vol 46, pp. 113-122, 2005.

[12] K. M. Rahman and S. Hiti, "Identification of machine parameters of a synchronous motor," IEEE Trans. Ind. Appl., vol. 41, no. 2, pp. 557-565, Mar.-Apr. 2005
[13] L. Chedot, G. Friedrich, and A. Cross, "Saturation model for interior permanent magnet synchronous machine application to a starter-generator," in Proc. 39th IAS Annual Meeting, Seattle, USA, 3-7 Oct. 2004, vol. 1, p. 70

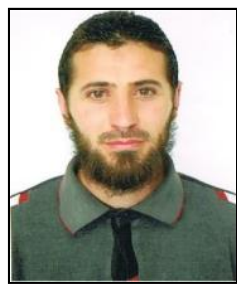

Bella Zaghdoud was born in Annaba, Algeria. He received the BS and MS degrees in Institute of Electrical Engineering from University of Badji Mokhtar Annaba, Algeria, 2007 and 2009, respectively. $\mathrm{He}$ is currently a $\mathrm{PhD}$ student at Electrical Engineering Department, University of Annaba, Algeria. His research interests include electrical machines: modeling, parameters calculation and control, power converters.

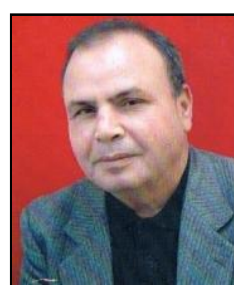

Abdallah Saadoun received his MSc from University of Liverpool, UK in 1989. He got his DC degree in 2007 from university of Badji Mokhtar, Annaba. Currently he is an associate professor in the Institute of Electrical Engineering and he is a member of the FP Laboratory at University of Annaba. His research interests are on power electronics, power converters, design of electrical machines and control. 